\title{
Causalidad Psicobiológica y Pluralismo
}

\author{
Psychobiology Causality and Pluralism
}

Dr. Carlos Javier Blanco (cblancomartin@yahoo.es) Facultad de Filosofía, Universidad de Oviedo (Oviedo, España)

\begin{abstract}
I present different approaches to psychological causality usually neglected. The debate between mechanism and dualism in psychology has obscured other pluralistic philosophical positions. I begin by setting out Schopenhauer's position, the "analogic" one, which includes, in a pluralistic view, diverse causations (mechanical, stimulate, and motive reasons) but with a monism of the will at the noumenal level. Then, I review other approaches in psychology and biological sciences: dialectical, constructivist and biosemiotics. All agree to see reality as plural and self-constituted.
\end{abstract}

Key words: psychological causality, dialectical process, biosemiotics, constructivism

\section{Resumen}

En este trabajo presento distintos enfoques sobre la causalidad psicológica normalmente desatendidos. El debate entre mecanicismo y dualismo en la psicología ha oscurecido otras posiciones filosóficas pluralistas. Comienzo por exponer la postura "analógica" de Schopenhauer, que incluye -de forma pluralista- una diversidad de causaciones (mecánica, estimular y causalidad por motivos) pero con un monismo de la voluntad en el plano nouménico. Después reviso otros enfoques dialécticos en la psicología y en las ciencias biológicas: dialécticas, constructivistas y biosemióticas. Todos ellos coinciden en ver la realidad como plural y autoconstituida.

Palabras clave: causalidad psicológica, dialéctica, proceso, biosemiótica, constructivismo

\section{Introducción}

El estudio de los fundamentos filosóficos de la psicología es importante pese al programa positivista imperante, que quiere hacer de esta ciencia -cada vez con mayor autoritarismo- un saber exento de cualquier implicación epistemológica u ontológica. El positivismo se traduce en la práctica universitaria en un recorte y hasta prohibición expresa de ahondar en cuestiones históricas y filosóficas e insiste en entender la ciencia del psiquismo como un saber ya hecho y plenamente neutral, perfectamente dotado de herramientas estadísticas y neurocientíficas. Las introducciones groseras a la ciencia de la psicología se detienen en la polémica entre un monismo materialista, más o menos mecanicista, y un dualismo cartesiano que, evidentemente, conserva todo el mecanicismo en lo referente a la res extensa (el cuerpo, el cerebro). El psicólogo ingenuo y el universitario formado en el positivismo a menudo tienden a creer que la psicología filosófica está superada, y que los dos cuernos del dilema son monismo y dualismo. Creo que no es así. Pienso que, desde un materialismo pluralista, desde un enfoque ontológico dialéctico, las categorías de la vida y del psiquismo ofrecen panoramas mucho más complejos y ricos. Sin pretender ser exhaustivo, ofrezco críticamente una serie de enfoques pluralistas de causalidad psicológica con el fin de contribuir a ampliar esta visión de la psicobiología. 


\section{Causalidad psicobiológica}

Comenzaré por la concepción schopenhaueriana de casualidad y su triple ordenación jerárquica: casualidad mecánica, estímulo y motivo. Creo que es una buena manera de aproximarse al pluralismo fenoménico (física, biología y psicología) que, en su caso, se remite a un monismo riguroso en el orden trascendental: la voluntad como cosa en sí y verdadera esencia o fuerza de toda la naturaleza:

"Llamo causa en el sentido más estricto de la palabra a aquel estado de la materia que, al provocar otro con necesidad, sufre él mismo un cambio de la misma magnitud que el que causa, lo cual se expresa con la regla «acción y reacción son iguales». Además, en la causa propiamente dicha, la acción crece en proporción exacta con la causa y, por lo tanto, también la reacción; de manera que, una vez conocido el modo de acción, a partir del grado de intensidad de la causa se puede medir y calcular el grado del efecto, y viceversa. Tales causas en sentido propio actúan en todos los fenómenos de la mecánica, la química, etc., en suma, en todos los cambios de los cuerpos inorgánicos. En cambio, llamo estímulo aquella causa que no sufre ninguna reacción adecuada a su acción y cuyo grado de intensidad no es paralelo al del efecto, el cual no puede así calcularse conforme a él: antes bien, un pequeño incremento del estímulo puede ocasionar un gran aumento del efecto o también, a la inversa, suprimir totalmente el efecto anterior. De esa clase es toda acción sobre los cuerpos orgánicos en cuanto tales: así pues, todos los cambios orgánicos y vegetativos del cuerpo animal se producen por estímulos y no por meras causas. Pero el estímulo, al igual que todas las causas en general, como también el motivo, nunca determina más que el punto en el que irrumpe la manifestación de toda fuerza en el tiempo y el espacio, pero no la esencia interna de la propia fuerza que se manifiesta y que, conforme a nuestra deducción anterior, hemos conocido como voluntad; a ella atribuimos, pues, tanto los cambios inconscientes del cuerpo como los conscientes. El estímulo se mantiene en el punto medio, realiza el tránsito entre el motivo, que es la causalidad mediada por el conocimiento, y la causa en sentido estricto. En unos casos particulares se halla más cerca del motivo y en otros de la causa" (Schopenhauer 2004:137-138).

La filosofía de Schopenhauer, idealista como es en el aspecto gnoseológico (El Mundo como Representación) y metafísico (El Mundo como Voluntad), contiene, no obstante, importantes trazados de corte materialista. Un materialismo, no pocas veces, de la más cruda índole. Me he dedicado a este asunto en otra ocasión, y de la misma opinión fue en su día Oswald Spengler. Este último había llamado la atención sobre el carácter prácticamente darwinista de la obra clásica de Schopenhauer. Un mundo doloroso y absurdo, en el que no cabe encontrar sentido ni finalidad. Un derroche de vidas, esfuerzos, afanes, de fuerzas litigantes sumidas en la sórdida competencia y guerra de todos contra todos. El afán de sobrevivir como individuos y de perpetuarse como especie, junto con las artimañas que la madre naturaleza ha urdido para engañarnos, añadiendo a ciertos animales, como somos los hombres, una inteligencia que es raíz de toda ilusión. Artimaña fue creernos inteligentes y conscientes, dones "superiores" que sirven de extensión del aparato instintivo en orden a garantizar la conservación y la perpetuación. Genitales, boca y estómago tienen sus correspondientes instintos en el mundo orgánico, pero también presentan homologías en las funciones éticas y racionales, de que tan orgullosos nos sentimos. A su vez, ese cerebro y esa racionalidad y moralidad tan "humanas" están al servicio de una voluntad que nada sabe de individuos ni de especies, que se sirve de todo trozo individuado de vida, pues solamente ella, la voluntad, como Dios ciego e inconsciente es la única cosa en sí de la vida. El terrible secreto que se agazapa tras de todo. 
El materialismo de Schopenhauer, ejercido con rigor y crudeza en todo el ámbito del mundo como representación (mundo fenoménico, diría Kant) exige un mismo monismo radical en el ámbito transfísíco: más allá de la naturaleza, y moviendo los títeres de la vida y la materia, se alza la terrible voluntad. Es ésta, la voluntad, el impulso ciego que impone un único y fundamental principio: seguir siendo. Todos los seres, inertes o vivos, transmiten ese impulso y cumplen, a cada uno acorde con su naturaleza, con el imperativo, el instinto o la ley natural que llevan escrito en su ser. De forma adecuada a su naturaleza constitutiva, todos siguen el principio de seguir siendo. El ser moral (el hombre) como orden imperativa, el ser animal como instinto de conservación y de reproducción, y el ser inerte, como ley física a la que se somete.

Precisamente, este esquema de monismo transfisico (la voluntad sustituyendo al Dios de la ontoteología) y su adecuación analógica al plano de los distintos seres físicos existentes en el mundo de la representación, pone en conexión la filosofía de Schopenhauer con las teorías escolásticas, a las que en cierto modo resucita. La concepción materialista de nuestro filósofo, en lo que al mundo representado hace, incorpora una aceptación del más crudo determinismo newtoniano. La causa (Ursache) en los fenónemos físicos, es idéntica al efecto (Wirkung). La acción y la reacción son iguales de acuerdo con la regla newtoniana ["Wirkung und Gegenwirkung sind sich gleich"]. Pero al pasar al orden orgánico (en el que los seres vivos gozan de la capacidad de automovimiento, se rigen por los instintos y luchan por su existencia, por encima y orientando las causas físico-químicas a las que también se atañen), Schopenhauer exige la consideración del estímulo (Reiz). El estímulo es una causa no adecuada a su efecto. Los estímulos, causas sui generis en el mundo orgánico, son causas desproporcionadas a sus efectos.

El filósofo de Danzig sitúa al estímulo en un punto medio: entre la causalidad mecánica -ciega al conocimiento- y el motivo, que propiamente es una causalidad mediada por el conocimiento. La biología ofrece a nuestra mirada esa especie de capa intermedia entre la física y la vida mental, donde acontecen los fenómenos orgánicos que, en puridad, carecen de fuerza específica. No hay "fuerzas vitalistas" que oponer a las fuerzas mecánicas. Los estímulos y sus reacciones orgánicas son puntos de expresión de la voluntad metafísica que se esconde detrás de esa relación entre causas y efectos de la biología. El estímulo es un punto de acceso (Eintrittspunkt) de la única fuerza que mueve el mundo, la voluntad. La voluntad como esencia transfísica es ajena al espacio y al tiempo, más cuando se manifiesta ha de hacerlo por medio de estas ventanas o puntos de contacto entre el mundo como voluntad y el mundo como representación. La ilusión del hombre, la de que es un ser consciente, le hace ciego a los impulsos recibidos desde el plano metafísico. Cree el hombre poseer una voluntad personal, propia, e ignora que ésta voluntad y conciencia individuales no son otra cosa que puntos de contacto -más elevados, sutiles y tardíos en cuanto a su surgimiento en la evolución biológica- pero puntos de contacto al cabo, entre la deidad ciega e impersonal, la voluntad, y su teatro de marionetas, el mundo físico, el plano fenoménico con su trabazón de causas. El motivo, presente en los mamíferos superiores cuando menos, y de entre ellos el hombre, es la causalidad sui generis del individuo complejo que, haciéndose la ilusión de su libertad y conciencia cumplirá así más eficazmente los designios en absoluto libres y conscientes de la voluntad. El motivo es la causalidad mediada por el conocimiento y este conocimiento, lejos de suponer un corte radical en la escala de los seres, o en la escala de los determinismos, no es más que una modulación en la que se manifiesta de forma más sutil la omnipresente actuación de la verdadera fuerza, la voluntad.

Dice Schopenhauer: "Vemos así que aquí, en los grados más bajos, la voluntad se presenta como un ciego afán, una agitación sombría y oscura alejada de toda cognoscibilidad inmediata. Es la 
forma más simple y débil de su objetivación. Como ese ciego afán y aspiración inconsciente aparece aún en toda la naturaleza inorgánica, en todas las fuerzas originarias que la física y la química se ocupan de investigar y de llegar a conocer sus leyes; cada una de esas fuerzas se nos presenta en millones de fenómenos de la misma naturaleza y regularidad, que no manifiestan huella alguna de un carácter individual sino que simplemente se multiplican en virtud del tiempo y el espacio, es decir, del principium individuationis, como se multiplica una imagen en las facetas de un cristal" (2004:179).

La voluntad es impulso, afán, ímpetu (Drang). Si a partir de los "puntos de contacto" en el mundo como representación vimos que en éste rige el más crudo materialismo, y un determinismo modulado según el nivel de organización de la materia (causalidad mecánica, estímulo, motivos), ahora podemos ver que ese impulso esencial que es la voluntad -en el mundo como voluntad transfísica, como cosa en sí- no hay ley ni norma, no hay causa final ni sentido: es este dios schopenhaueriano (o esta negación de todo dios o trascendencia) una nada llena de fuerza. Nada más que fuerza, impulso, ímpetu. Nada hay de representación ni conocimiento en él mismo: es el anhelo sin la más mínima conciencia. Acaso en el hombre y en otras especies animales superiores se den interferencias y mixturas entre "facultades" cognitivas y volitivas. Eso sucede en el individuo, quien se deja engañar por su voluntad individualizada, equívoca manifestación de la única voluntad que guía su conducta. La voluntad se multiplica en millones de individuos, sin que ella misma se vea afectada en su simple esencia. Estos organismos con voluntad prestada e ilusiones propias -en virtud del principio de individuación- difieren numéricamente entre sí, pero en un plano metafenoménico son todos ellos órganos o tentáculos del terrible Ser ciego, que los ha creado -paradoja misteriosa en Schopenhauer- para imponerse mejor y superar su ceguera inconsciente.

Aunque objetivándose con mayor claridad a cada grado, también en el reino vegetal, donde el nexo de sus fenómenos no son ya las causas propiamente dichas sino los estímulos, la voluntad sigue actuando de forma totalmente inconsciente, como oscura fuerza motriz; y lo mismo ocurre en la parte vegetativa del fenómeno animal, en la generación y formación de cada animal y en la conservación de su economía interna, donde su fenómeno es determinado necesariamente por meros estímulos. Los grados ascendientes de objetividad de la voluntad conducen finalmente al punto en que el individuo que representa la idea no puede ya obtener su alimento a base de simples movimientos por estímulos; porque el estímulo hay que aguardarlo, pero aquí el alimento está especialmente determinado; y al haberse incrementado progresivamente la variedad de los fenómenos, el agolpamiento y la confusión se han hecho tan grandes que unos perturban a otros, y sería demasiado improbable la coincidencia de la que el individuo movido por meros estímulos ha de esperar su alimento. De ahí que este haya de ser buscado y seleccionado a partir del momento en que el animal se ha desgajado del huevo o del vientre materno en el que vegetaba inconsciente.

La formación de cada animal se entiende como un brotar espaciotemporal y corpóreo de aquella fuerza oculta, el impulso de una voluntad que también es responsable del estado interno. Los organismos inferiores dependen de la presencia inmediata del estímulo, más los dotados de un sistema nervioso más elevado no aguardan a su aparición, sino que más bien lo esperan. La individuación de la voluntad en un organismo conoce también su ontogénesis: de la pasividad ante los estímulos, el organismo adulto deviene activo buscador. Hay una conexión progresiva evidente entre la fase meramente vegetativa, inconsciente en la que viven los seres inmaduros en sus 
primeros momentos del desarrollo y la individuación de segundo grado, la ontogénica, en la que un organismo ya ha logrado su autonomía en la búsqueda del alimento.

\section{Frente a la jerarquía fenoménica, una dialéctica entre naturaleza y cultura}

Somos naturaleza y somos cultura, y también somos ambas cosas a la vez. Al defender semejante trivialidad, no nos cabe duda de un hecho: somos igualmente herederos del idealismo alemán. Un esquema materialista dialéctico (no monista), por el mismo pecado original, también es heredero del idealismo. Hay un hiato entre naturaleza y cultura, en primer lugar, asumido desde que el cristianismo rompió el antiguo monismo grecorromano. Con posterioridad a ese hiato, los filósofos han tratado de establecer una dialéctica o algún esquema de relación entre dos mundos divorciados. Se puede impugnar el hiato mismo, la premisa. Pero al hacerlo, sobrevolamos la tradición filosófica. Se puede, por el contrario, "dialectizar" el hiato, poniendo la lupa en procesos concretos donde se den infiltraciones de ambos mundos y en ambas direcciones.

Esas infiltraciones de la naturaleza y la cultura son las que deben interesar al materialista no dogmático. Esas infiltraciones que saltan el abismo idealista, que consideran el transfondo psicobiológico de la relación entre naturaleza y cultura, serán objeto de estudio en este ensayo. La propia constitución del individuo "anuda" las hebras que abstractamente separan naturaleza y cultura como dos reinos aparte.

El hiato entre cultura (relaciones sociales, verbigracia) y biología ha de replantearse como una teoría del desarrollo (ontogénesis). Esta teoría no es solo una descripción del proceso de "llegar a ser persona", de la infancia como punto de partida sino, como afirma Robertson (1996), es una teoría del proceso vital completo, que incluiría la senectud. Los modelos reduccionistas (léase la psicología evolucionista, a su vez inspirada por los enfoques computacionales) tienden a ver la transmisión inter-generacional como una simple difusión de bits, de memes o de quantos discretos de información que pasan de unos cerebros a otros. Con ello se desvirtúa por completo el marco darwinista y psicoevolutivo, en sí mismo dialéctico. No son los viejos los que inculcan "virus" o "paquetes" de información a los jóvenes por medio de unos canales unidireccionales y lineales.

Debería re-evaluarse el concepto de ontogenia, y ese es un objetivo principal de nuestro trabajo. ¿Es esta una categoría meramente biológica, y, por lo demás, genérica? Así parece cuando la estudiamos de la mano de biólogos y científicos sociales proclives al reduccionismo. Observemos con cierto detalle por qué el mismo concepto de ontogenia ha sido objeto de recortes reduccionistas.

Primero. Esta categoría parece ser objeto de una restricción cronológica: se limita al periodo de desarrollo fetal y a la vida del recién nacido. A su vez, estos primeros meses y años de vida. Segundo. Estos procesos ontogénicos se suelen estudiar solo desde una forma "cerebro-céntrica". El cerebro es visto como una especie de caja negra pre-cableada y apta para recibir las instrucciones del entorno. Contra este doble reduccionismo, temporal y cerebrocéntrico, coincidimos con Robertson al defender una teoría constructivista (o dialéctica) de la reproducción social. Una especie de difusionismo biologicista ha empobrecido la teoría social. Educar y educarse sería un proceso análogo a la recepción de un virus o un input.

Como dice Robertson: "It is ironic that the merger of Darwinian theory and cognitive psychology should have gravitated to diffusionist models of culture, the cibernetically-imagined migration of cultural fragments from one brain to another, rather than the interpretations of individual cognitive development in its social contexts. Darwinian theory remains remote from the unfolding 
lives of individual people who labour over many years to form and perpetuate the social systems on which we all depend" (1996:593).

El meme, un concepto análogo al de gen, pretende ser una unidad de evolución y selección en el plano cultural. J.S. Wilkins (1998) sostiene que la de meme es una noción que ha llegado a ser mal utilizada. Especialmente cuando se le define análogamente a un virus, a un patógeno que se expande, los memes en tanto que replicadores serían lo que el propio R. Dawkins (2000) denomina en El Gen Egoísta "los virus de la mente", una metáfora difusionista a la par que reduccionista que ha gozado de predicamento en la neurociencia (Edelman, Dennett, Calvin) o en la epistemología (Campbell, Popper).

Conviene resaltar que el "cerebrocentrismo" es un enfoque particular de lo que en biología, y por extensión, en todas las ciencias sociales se puede llamar "organocentrismo". Entender siempre y en todo momento el organismo como un punto de partida, un comienzo a su vez fenoménico que resguarda el plano esencial y reduccionista: los genes. Según Ingold, los neodarwinistas solo pueden concebir la evolución en términos de cambio en la distribución y frecuencia de los genes. El fenotipo habría de ser el output, el resultante de un input genético y unas reglas epigenéticas. Pero, dice con acierto Ingold (1990), este punto de vista implica una idea de organismo como ente cosificado, como sustancia, por más que se regrese desde ella hacia sus genes, auténticos dioses ex machina que lo explican todo: fisiología, organización, comportamiento.

\section{El enfoque procesual de Tim Ingold}

Se acerca mucho más al enfoque dialéctico la consideración procesual defendida por Ingold. La ontogenia, el crecimiento, se entiende como un proceso autogénico, el crecimiento es un movimiento de autoconstrucción más que de revelación de informaciones ocultas. Y lo que Ingold defiende para la autoconstrucción de las partes puede sostenerse también para referir las relaciones entre el organismo y el ambiente. La ontogenia centrada en el suceso (event) se movería igualmente en dos escalas: (1) autopoiesis (ontogénesis estricta) y (2) ecología (construcción de relaciones ambientales). Hay un tercer nivel (3) en el que la visión procesual de Ingold podría generalizarse en la búsqueda de infiltraciones entre naturaleza y cultura: las relaciones sociales, la relación individuo-sociedad. La sociedad no es el input que va conformando al individuo (como corriente de memes que lo invaden, le "influyen" o "contaminan"). Más bien, el individuo es un organismo que se va construyendo como persona a través de relaciones sociales y procesos ab initio lingüísticos (recuérdese aquí el enfoque de Vigotsky). La memética, la psicología evolucionista en general, así como la teoría de la ecoevolución genes/cultura son ejemplos típicos de los dualismos de corte idealista que, desde Kant y desde los grandes idealismos germánicos no han podido ser superados hasta hoy. Todavía hoy la biología moderna, bajo el disfraz de un vocabulario técnico y especializado, distingue el genotipo y el fenotipo, y esto es un trasunto del dualismo. Con esta distinción, los individuos son vistos como productos, como resultados acabados de la evolución. El fenotipo será el efecto de unas determinadas causas genéticas, ambientales, culturales. El dualismo genérico se desdobla ad intra, refiriéndose a la construcción del cuerpo como una "interacción" de la herencia y del ambiente. De tal dualismo no escapa la teoría de la co-evolución gen-cultura (Laland, Kumm, Feldman). Tal teoría sirve de marco para engullir cómodamente toda la antropología cultural dentro de las fauces de la biología. En esa reducción, la misma cultura aparece como un sistema de procesamiento de información dada, análogo al genotipo en buena medida, como análogo es también el neologismo "meme", entendido como unidad que entra en dicho procesamiento, y que "inocula" cerebros. Se trata de 
explorar una analogía entre el pool genético y el pool simbólico, así como sus interacciones. Basándose en modelos de genética poblacional que incluyan la transmisión cultural, el papel de ciertas prácticas (selección sexual, abortos sesgados según el sexo, infanticidios, etc.)

El punto de partida de Ingold es el organismo, pero no el organismo como fenómeno desde el que habría que regresar a un código genético esencial, sino el organismo como sistema en autoconstrucción (y este proceso de autoconstrucción es una sucesión de acontecimientos). El organismo como producto o ente acabado se entiende al modo de un sistema cerrado. De esa manera, cerrando esta entidad, la biología, que oscila entre constituirse como una ciencia de los genes o una ciencia de los organismos, se asegura su ubicación en el caso primero. Para ello, una vez que el determinismo genético absoluto es indefendible, pero, a la vez, con el lamarkismo derrotado, los biólogos modernos segregan los dos tipos de causación, 1) la causación próxima (epigénesis) de 2) la causación última (evolución). En esta última clase cabe defender el papel del organismo individual como "conductor" de la evolución, pero las necesidades de segregación de la biología genocentrista bloquean esta perspectiva (Ingold 1990:211).

\section{Causas últimas y causas próximas}

Esta distinción entre causas últimas y causas próximas procede de 1961 de la mano de Mayr. Ambas deben considerarse necesarias para la comprensión completa de un determinado fenómeno biológico. Las causas últimas involucran la historia, y se incorporan al sistema a través de muchos miles de generaciones. Las causas próximas incorporan mecanismos inmediatos responsables de los efectos en cuestión. Como sostiene Michael R. Dietrich (1998) fue en esa década de los 60 cuando el término "información" empezó a usarse como palabra comodín para describir las interacciones y factores causales en las proteínas, el RNA, el DNA, etc. El nivel más básico y reductivo (proximal) requería de un vocabulario informacional.

La réplica del biólogo R.A. Hinde (1991) a Tim Ingold sería la siguiente: la evolución solamente es una parte de la biología. En rigor, en la ciencia biológica se dan los niveles que siguen a continuación: 1) causación, 2) desarrollo, 3) función y 4) evolución.

El punto 2, el desarrollo (development) involucra relaciones entre partes y estratos que suelen arrancar desde el celular hasta el nivel del organismo. De acuerdo con la visión aquí expuesta, y compartida también por Ingold, la dialéctica es constructiva y va más allá del interaccionismo. Este marco de la interacción suele ser una modificación del dualismo (como el dualismo que lleva décadas manejando la distinción nurture/culture), concediendo el papel de factores a los dos polos del producto (naturaleza x cultura). Hay una dialéctica entre escalas, pero ¿con límites? Hinde dice que sí: la escala supraindivual (grupos, relaciones entre grupos, sociedades...).

El enlace entre una biología reductiva y un enfoque computacional es el que preside la psicología evolucionista. En un plano meramente discursivo ésta disciplina se reclama deudora del neodarwinismo, pero lo cierto es que adopta más bien un enfoque lamarkiano. La cultura sería un flujo de información rápido y mudable en cuanto a sus efectos selectivos, mientras que los genes obedecerán a estrictos procesos selectivos (Robertson 1996). La evolución cultural es mucho más rápida que la biológica, sujeta a mutaciones bruscas (p.e. los inventos). Los cerebros "infectados" por la mutación se convierten a su vez en fuentes de propagación de ondas dotadas de nuevo poder para la infección. La multiplicidad de receptores implica a su vez una multitud de fuentes emisoras. Esa multitud de cerebros (en eso consiste una cultura, en este sentido no dialectizado) incluso es vista al modo de un enjambre (swarm). 


\section{Biología y enjambres orgánicos. "Cuerpo" y "curso" de la evolución}

El concepto de cuerpo y cerebro como enjambre lo encontramos en Jesper Hoffmeyer en su obra Signs or Meaning in the Universe. La acción integrada y jerarquizada de una población, un organismo, un cerebro, etc. no tiene por qué deberse a un órgano ejecutor central, sino a una colección de pequeñas entidades que establecen entre sí relaciones semióticas. También Sebeok con su concepto de endosemiosis constituye un hito en la biosemiótica: la endosemiosis es un concepto que cobra importancia en la medicina y la fisiología no reduccionistas.

Los enjambres, las multitudes, como modelos para la desustancialización del organismo son interesantes. Nos recuerdan que un organismo, aunque es más que una colonia de células, de unidades funcionales vivientes, tampoco deja de ser eso mismo: una colonia. La diferencia entre el reduccionismo y el enfoque biosemiótico estriba en la manera en que entran en relación (aunque sea metafóricamente) las unidades: por "contagio" o por "comunicación". En el modelo biosemiótico el intercambio de mensajes se da a todos los niveles de la vida y parte siempre de la acción. Como dice Sharov, al principio era la acción. Primero viene la acción, y después ha de tener lugar la interpretación. Todo mensaje implica un código estructural. Acción y estructura son las dos caras de la misma moneda. La cibernética comenzó siendo una teoría general de los sistemas de control que abarcaba en un mismo esquema (de fusión) las máquinas y los organismos vivos. Pero ante el fracaso como teoría general de la vida (no así como fuente de modelos análogos de los seres vivos y sus partes), un fracaso que fue debido a su cariz totalitario y cerrado, ésta abrió sus compuertas hacia un paradigma biosemiótico, más pluralista y abierto. En este paradigma neocibernético, el cambio evolutivo a largo plazo se puede ver como un enjambre de comunicaciones en el que la captación de sentido lleva la voz cantante, más allá de meros fenómenos estadísticos que reflejan cambios de estado en sistemas fisicalistas. Sharov presenta este enfoque como una superación de la cibernética y, a la vez, como un desarrollo semiótico fuertemente enraizado en ella.

La cultura misma podría ser entendida como enjambre de unidades que intercambian señales o "infecciones" (sociobiología, psicología evolucionista) o bien símbolos dotados de sentido (por medio de interpretaciones según la biosemiótica). Pero tenemos que decir, desde el enfoque dialéctico, que en ambos casos hay un esquema "plano" de cultura. Para enriquecer este plano, para dotarle de una dimensión -digamos- volumétrica habría que precisar más el concepto.

Díaz de Rada y Velasco (1996) distinguen dos sentidos antitéticos, hasta cierto punto, de "cultura": como transmisión y como adquisición. La antropología contemporánea ha ido desplazando el acento hacia ésta última acepción, mucho más constructiva, menos plana. Tal concepto va más allá de la metáfora que equipara la adquisición con el hecho de contaminar un cerebro u otorgar significado a un flujo de señales, convertidas en símbolos. Ahora está dándose un extenso campo de metáforas de entre las cuales la idea de cultura permanece dotada de un gran nivel de abstracción. Los autores también recuerdan que la cultura, clásicamente, ha sido vista como un pool, como un depósito de representaciones listas para ser incorporadas en cada generación (p.e. por vía de la escuela, dentro de una sociedad letrada). Frente a esto, los autores optan por una des-objetivación de la cultura. Y para des-objetivar hay que remitirse a distinciones más profundas y genéricas que la de naturaleza y cultura. Hemos de referirnos a la distinción entre estructura y proceso, ya implícita (por lo menos implícita) en Aristóteles, y que cobra toda su plenitud en Hegel. El filósofo alemán es el gran teórico del proceso. De tal idea filosófica está plagada toda la ciencia contemporánea, de la que puede servirnos de ejemplo la distinción que Ferdinand de Saussure 
establece entre sincrónico y diacrónico, a su vez fuente de inspiración en las demás ciencias humanas (especialmente la antropología y la sociología), más allá de la lingüística. La distinción que hace Gustavo Bueno (1991:229) entre "curso" y "cuerpo" pretende ser una dialectización de esa distinción, que no ha de tomarse como absoluta sino como abstracta. Se habla así de "cuerpo" en cuanto se segrega la génesis o la historia de un fenómeno procesual (Bueno 1991:231).

El "cuerpo" no biológico, sino cultural, el soma de una cultura, se enfrenta dialécticamente a su curso. $Y$ en ese enfrentamiento dialéctico (buscado, pretendido por quien lo pone en práctica) aparece necesariamente la cuestión de si existen cursos universales. Una interpretación posible, y por ende una interpretación metafísica, del idealismo hegeliano sería que al "historizarse" la ontología, como hizo Hegel, se anulase precisamente la propia historia. La historia perdería su especificidad ontológica (ontología especial) al quedar devorada por una ontología general en la que "todo es historia", proceso, sí, pero proceso en el sentido de "despliegue". Y en puridad, un despliegue es una mera secuencia de acontecimientos pre-establecidos, de acuerdo con unas reglas precisas, predeterminadas.

En biología, estas reglas predeterminadas que bloquean su sentido histórico, pueden precisarse como algoritmos. El algoritmo básico a escala orgánica sería una lista de reglas cuya ejecución adecuada permitiría pasar a la siguiente generación. La psicología evolucionista parte de una evidencia neuropsicológica: hay unas áreas en la corteza del cerebro que, de manera innata, incorporan dispositivos (devices) que, de manera proximal sirven a los efectos de lograr las metas de una causación distante, la de índole adaptativa o, stricto sensu, causación evolutiva.

No deja de percibirse aquí una cierta circularidad argumental: la evolución "ha dispuesto" esos dispositivos cerebrales (computacionales y próximos) con el fin de que los mismos sirvan para la ejecución eficiente del "gran algoritmo" (distante, finalista, evolutivo) que es la adaptación y supervivencia.

Cualitativamente, un sistema biológico, y especialmente uno tan complejo como el cerebro, no resiste ninguna comparación con los computadores. De todas maneras, siempre cabe la sospecha de que lo cualitativo esconda un prejuicio esencialista. Pero es que en el aspecto cuantitativo, tampoco hay mucho donde agarrarse. D. H. Hubel escribía hace años: "Parece bastante simple para las células ser manufacturadas biológicamente, y de hecho, las neuronas son producidas en número prodigioso. No parece tan fácil aumentar los elementos de una computadora, aunque los números se eleven rápidamente. Sin embargo, si se considera que los elementos del sistema nervioso no son las neuronas, sino las sinapsis, me es difícil imaginar que las computadoras puedan nunca darles alcance. Nadie desearía verse obligado a contar el número de sinapsis del cerebro pero cifrarlas en 10 elevado a 14 (100 billones) no resulta ningún dislate" (Hubel 1979:9).

En las neurociencias, la cuestión cuantitativa y la cualitativa va estrechamente unida, y el elevado número de neuronas que pueblan un cerebro, así como el mucho más numeroso número de conexiones que lo interconectan, da pábulo a la reducción cuantitativista: la elevada complejidad del cerebro es consecuencia directa de y objeto reducible a un asunto de cantidad. Esta perspectiva menosprecia la organización cerebral. El aspecto formal que un "conductismo de las neuronas" (como el D. O. Hebb, por ejemplo) no podrá resolver. Pues es verdad que el psicobiólogo Hebb abrió cauces en la investigación para estudiar cómo las células individuales o grupos concretos de células individuales por mero "uso" o "hábito" son capaces de iniciar y mantener conexiones con otras unidades o grupos. Pero tal "conductismo de neuronas" sin un punto de vista formal (organizativo) tendría que dibujarnos el mapa de un cerebro con el aspecto 
de una masa indiferenciada de millones de unidades y conexiones que se crean, se rehacen y se deshacen constantemente sin unas estructuras anatomofuncionales estables que sirvan de parámetros a tales acciones. Esta cuestión nos remite al papel que las ciencias formales (matemáticas, lógica) podrían desempeñar en la psicología. Resulta interesante leer la respuesta que Hebb (2002) le da a Mario Bunge sobre los dos defectos principales de la psicología como ciencia. Hebb sostiene que la psicología no es menos científica por el mero hecho de no contar con estructuras formales estables, pues éstas llegan a construirse tras un proceso empírico en el que la psicología está inmersa, justo como las demás ciencias naturales. El propio Hebb, con sus investigaciones sobre asambleas neuronales sostiene que, al menos, las correlaciones estadísticas entre actividades neuronales y comportamentales ya se encuentran en curso. Bunge achacaba estos dos defectos a la ciencia psicológica: a) que le falta matematización y b) que le faltan estudios neurobiológicos que la sustenten. Como se ve, la propia labor de la carrera científica de Hebb, más que sus propias palabras, constituyen toda una respuesta al filósofo argentino.

Sin entrar a valorar los propios prejuicios positivistas de Bunge a la hora de señalar carencias de una disciplina científica, la respuesta de Hebb que comparte con Bunge la filosofía general del monismo psiconeural, replica al filósofo argentino que (b) ya es un proceso que lleva tiempo en marcha (él mismo es protagonista y figura clave del mismo), pero que en cuanto a la objeción (a), ésta falta de matematización no es requisito esencial para la psicología como ciencia. De hecho, la psicobiología actual en una medida amplísima, cuando "matematiza" sus investigaciones lo hace con un sentido meramente estadístico y sus investigaciones son en gran parte "correlaciones" entre fenómenos biológicos y conductuales. Una correlación estadística como contenido de una hipótesis empírica que conecte lo cerebral y lo conductual, difícilmente es algo más que una yuxtaposición, y tal yuxtaposición suele dar sentido y justificación al doble sintagma: psico (de psyke) y biología.

En realidad, tal enfoque cuantitativo (estadístico) de la psicobiología es el que estuvo presente desde los comienzos mismos de la psicobiología, como en el caso de K.S. Lashley, otro conductista metodológico.

Por medio del conocido método de las disociaciones y los correlatos estadísticos entre actividad humana y áreas cerebrales, se ha ido dando paso a una neuropsicología más funcional, que sustituye el antiguo localizacionismo por el concepto cognitivo de módulo. La psicología cognitiva (y especialmente autores como J.A. Fodor) ha acogido de buen grado esta propuesta organizacional (léase formal o funcional). Es decir, una reorganización del cerebro no en términos de estructuras anatómicas que no correlacionan bien con la actividad funcional y sólo de forma compleja lo hacen con la fisiológica. La llamada "revolución cognitiva" consistió en buena medida en alimentar la esperanza de crear modelos funcionales de la mente que correlacionen de manera estable, consistente, etc. con la actividad funcional (mente, conducta). Un enfoque computacional de la mente es solo una de las propuestas. Como dice Eugene Charniak: ¿qué hacemos mientras llega una "revolución cognitiva" verdadera? Hace falta una teoría que reorganice el campo de la cognición: "There are no a priori reasons for believing that any of our current methodologies is more likely of, say, language comprehension than any of the others. Thus, we should accept our multiple methodologies, and wait for the day that one or other of them produce a theory around which we can all rally. However, even the existence of such a theory will still not eliminate the methodological bubble. We will all continue on, but now exploring the same theory" (Charniak 1984:269). 
La síntesis o convergencia de varios campos diferentes es lo que dará lugar a una revolución. En biología así ha sucedido con la teoría de la herencia en el siglo XX. La cuestión es si: 1) existe realmente la "ciencia cognitiva" y 2) si hay acuerdo en que existe una suerte de arquitectura funcional que cumple con el requisito de haber sido objeto de selección natural, como lo fue de hecho la anatomía de las especies vivientes.

De la cuestión epistemológica (1) ya nos hemos ocupado en otros lugares (Blanco 1997). De la cuestión (2) precisamos ahondar en el concepto de función y ofrecer de él una reconstrucción dialéctica (es decir, a la vez epistemológica y ontológica), lo cual supone explorar sus diversas relaciones con otros conceptos fundamentales.

Siguiendo una distinción muy útil, que debemos a J.C. Sánchez y J.C. Loredo (2005), en las ciencias de la vida actuales pueden distinguirse diversos tipos de darwinismo, interpretaciones diferentes que divergen precisamente en función del criterio que se maneje de lo "funcional".

a) El neodarwinismo "duro". Según los autores, éste cuenta con un truco: la plasticidad. Se admite en los casos difíciles una amplia norma de reacción, pero con un geneticismo en la base.

Este es el camino que sigue G. Simpson, autor que acepta la tesis de la sustitución: el hábito acaba convirtiéndose en instinto. Los instintos, por su parte, se dividen en perfectos o imperfectos. En el caso de los instintos imperfectos hablaríamos de programas genéticos que solo se dan por medio del aprendizaje.

b) Un neodarwinismo epigenético. En él se echa de ver que una experiencia ambiental modifica la dominancia o la preeminencia de un gen ya existente. En el fondo, este proceso no es una selección orgánica.

Hoy en día está abriéndose camino un neodarwinismo que podemos llamar "reformista", representado por Daniel Dennett. En él, la ontogenia funciona como una especie de banco de pruebas de la selección natural.

Loredo y Sánchez emprenden una crítica dudosa a Kant y a la biosemiótica. Cuando se refieren a la noción de símbolo, los dos autores mencionados no expresan debidamente el carácter relacional más allá de su cariz ora lingüístico ora mental, que es una de las principales aportaciones de los biosemióticos y de lo que podríamos llamar la biología teórica de raigambre kantiano. La crítica de Loredo y Sánchez se basa en que la noción de símbolo no contempla la noción de génesis, un prius (requisito previo) que, partiendo de Baldwin, sería exigible a toda reformulación teórica que se reclame constructivista (Sánchez y Loredo 2005:120). El constructivismo conjuga instinto y hábito, ambos serían recursos del genoma partiendo de un sujeto orgánico que sólo puede ser definido como actividad. Kant, si bien es la fuente de todo constructivismo moderno, pues a un tiempo huye del idealismo (berkelyano, platónico o racionalista) y del realismo empirista (aristotélico o moderno), que son -al cabo- dos trascendentalismos, no habría dejado de asumir un punto de vista trascendental que habría de ir mitigándose en la historia de la psicología experimental (Helmholtz y demás "fisiólogos kantianos", el pragmatismo americano, el propio Baldwin). Pero este relato histórico de la psicología como "naturalización del kantismo" y, por tanto, como consolidación de una verdadera teoría inmanente y constructivista del conocimiento, no hace honores al propio padre reconocido del idealismo trascendental (y constructivista) si asumimos con Eugenio Moya que "a pesar de los tópicos sobre el trascendentalismo, en la obra de Kant no encontramos una razón pura y unitaria, capaz de enfrentarse al mundo (y al propio cuerpo) para imponerle sus reglas y principios teóricos y prácticos, sino más bien una razón instituida por la 
naturaleza, de carácter modular, caracterizada por los continuos conflictos intermodulares y, por tanto, muchas veces incapaz no sólo de legislar aquél mundo, sino tan siquiera de gobernarse a sí misma" (Moya 2005:63).

No se puede dar una versión simplificada del kantismo. Kant planteaba una epigénesis de la razón. Las categorías contienen, desde el entendimiento, las bases que posibilitan toda experiencia en general. Moya niega que el frecuente uso de ideas contrapuestas como las de epigénesis y preformación en Kant tenga un sentido meramente metafórico y como traído por los pelos desde los contextos de la biología a otros, diversos, como son los de la teoría del conocimiento. Nada de eso. Con los conocimientos de que Kant disponía en embriología y en otras ciencias biológicas de entonces, el de Königsberg se lanzó hacia una solución ni empirista ni racionalista (preformacionista) del problema de la construcción. Kant fue un naturalista en un sentido que no contradice los elementos transcendentalistas de su filosofía: para él, los problemas epistémicos eran una extensión de los problemas biológicos (Moya 2005:66).

La visión de Moya sobre Kant es más bien la de un emergentista. Recuperando la idea aristotélica de continuidad de la naturaleza, los seres vivos formarían en su conjunto un todo orgánico o comunidad, más allá de su consideración atomística de seres discretos en competencia. Pero es que a su vez, el todo orgánico conformado por lo que llamamos "individuo" es una continuidad de funciones (módulos) de cuya actividad conjunta emergen las funciones anímicas y de entre ellas las cognitivas o epistémicas, que son, indudablemente, propiedades de la materia. Kant es para Moya, ciertamente, un materialista, pero no de la especie del materialismo reduccionista o fisicalista. Se trataría de un materialista emergentista.

Que Kant era un materialista de la especie emergentista lo prueba su concepto de Bildungstrieb, el impulso formador que poseen -según él- todos los seres vivos en orden a conservar, recibir, mantener su forma. Tal idea la recoge Kant de J.F. Blumenbach y debe ser entendido como algo distinto de los propios materiales constituyentes del organismo. Lejos de todo sustancialismo, Kant acepta este concepto como principio heurístico. La naturaleza puede ser descrita por medio de analogías y heurísticos que están lejos de ser leyes o principios de alcance ontológico (metafísico) pero dotados de evidente utilidad y comodidad en la investigación. En este sentido, Moya vincula estrechamente epigénesis y emergentismo: no solo hay una epigénesis biológica (embriológica, sobre todo) sino también psíquica. En la propia alma hay unos gradientes o estratos. Alma es una idea que no va a ser tratada en términos sustancialistas. Alma es en Kant una confederación de subsistemas mentales en interacción, dice Moya. Por descontando, el apriorismo kantiano no tiene nada que ver con el innatismo. Más bien, los compromisos del filósofo de Königsberg caen del lado del emergentismo. El alma como confederación de subsistemas orgánicos construye los conocimientos.

Esta reformulación de Kant en términos de modularidad, y también esta reformulación de la modularidad en términos kantianos, constructivistas y materialistas (que también está presente en los escritos de Moya) es, como mínimo, sugerente. Nos aparta de ciertos tópicos y asociaciones rutinarias. Por ejemplo, nos aparta del sesgo innatista que la obra de J. A. Fodor ha introducido en su enfoque de la modularidad de la mente. También nos aparta de las rutinarias caracterizaciones de Kant como idealista irreconciliable con el naturalismo constructivo.

La necesidad de introducir esquemas emergentistas ha ido en aumento dentro de los enfoques computacionales de la mente. A partir de un grosero funcionalismo basado en el modelo de máquina de Turing, los psicólogos, neurocientíficos y filósofos han ido aterrizando cada vez más en 
el sustrato cerebral para entender debidamente cómo éste órgano puede, de manera casi automática, producir "conocimiento". Por ejemplo, en el campo de la percepción Walter Freeman estudió cómo el cerebro transforma los mensajes sensoriales en percepción consciente casi al instante por medio de una actividad caótica, colectiva, que involucra millones de neuronas.

El caos puede ser la propiedad clave que diferencia a un cerebro de un sistema de inteligencia artificial, según Freeman. Pero ese caos se da en el seno de una actividad "modular" y múltiple, como resultado de órdenes motoras, reaferencias (feedbacks) y percepciones, preparando cada acto nuevo tomando como base los anteriores: "an act of perception is not the copying of an incoming stimulus. It is a step in a trajectory by which brains grow, reorganize themselves and reach into their environment to change it to their own advantage" (Freeman 1991:41).

Vemos aquí una combinación de modularismo y pensamiento emergentista, como el que estamos extractando en Moya y en Freeman. También existe en el enfoque biosemiótico de Claus Emmeche. Según este autor, los sistemas complejos son necesariamente emergentes y capaces de soportar una experiencia fenoménica. Son tres los requisitos para poder producir esta experiencia: patrones emergentes de movimiento, causalidad descendente (downward) y medio entorno (Umwelt).

La neurociencia, cada vez más abierta a enfoques computacionales no clásicos (no seriales, sino caóticos, conexionistas, etc.), por necesidad, ofrece no obstante una imagen solipsista de la actividad orgánica, reducida a computaciones múltiples y complejas de cerebros encapsulados. Es la corriente biosemiótica la que con más tenacidad y frecuencia se reclama heredera de la biología fenomenológica de von Uexkühl. En ella está presente desde el comienzo la cuestión de la conciencia, presente desde el inicio mismo de la vida, y que no ha de despacharse nunca como un mero deus ex machina.

\section{La Causación Descendente de Claus Emmeche}

Junto con Peirce y Leibniz, la tradición biosemiótica se remonta al mismo Aristóteles. El estagirita defendió la existencia de varios tipos de causalidad, además de la motriz: la final, la formal y la material. Estas causas co-actúan a muy diversos niveles dentro de cada proceso, y entre ellos se entremezclan los niveles conscientes y los inconscientes. Las causas se relacionan con los signos, pues en la biología siempre han de darse estos para que un organismo se comporte como algo más que un mero dispositivo mecánico: un organismo es intérprete de las relaciones en las que participa y, en este manejo e interpretación de los símbolos, se da la causalidad que Emmeche denomina descendente. Se entiende por causalidad descendente (downward causation) aquella acción que, partiendo de niveles más elevados en complejidad o de capas orgánicas más diferenciadas y evolutivamente posteriores, puede actuar sobre sustratos materiales más básicos.

La conciencia sería una forma de causalidad descendente y estructural, un tipo de causalidad estructural en el que la conducta de las neuronas individuales o de poblaciones neuronales queda gobernada por una instancia total. Las partes son incrustadas en un todo y por la acción del todo. Este hecho es situado por Emmeche en una perspectiva macro-evolutiva. Emmeche defiende un organicismo cualitativo que se reclama heredero del de Aristóteles y que rechaza las nítidas demarcaciones positivistas que se trazan entre ciencia y filosofía (Emmeche 2004).

Conviene distinguir organicismo y vitalismo. En la biosemiótica de Emmeche no se defiende la existencia de ningún "principio vital" o un alma ontológicamente separada de la materia física. Se trata de un enfoque emergentista, coincidente con el "materialismo kantiano" que Luis Moya 
observa en el filósofo de Königsberg. La biosemiótica se encuadra dentro de un cierto realismo de propiedades emergentes: no se puede negar que hay relaciones y propiedades semióticas en la naturaleza ni que, de una forma naturalista, hay una continuidad entre materia, vida y mente. Lo que sucede es que, frente a Uexkühl, la biosemiótica es decididamente evolucionista, y frente a Peirce, la biosemiótica es pluralista (no monista).

En los campos de la biología, a diferencia de los de la física, se necesitan conceptos funcionales. En el mismo nivel celular, en la escala de los organismos unicelulares, los seres pueden responder a estímulos potencialmente negativos. Estos estímulos que afectan a su homeostasis pueden ser identificados oportunamente por las células. Esta propiedad de la irritabilidad ha sido señalada clásicamente como concepto fronterizo, que nos hace pasar del nivel físico-químico a la biología.

Después vendrán los bio-cuerpos, células coordinadas para formar lo que Aristóteles llama vida vegetativa (Emmeche 2004:121). Aquí también hay una causalidad descendente (funcional). La totalidad del cuerpo actúa controlando o poniendo límites al crecimiento y diferenciación de células individuales.

Tras la vida vegetativa (células coordinadas) vendrá la zoología stricto sensu, el estudio de los movimientos animales, incluyendo los aspectos cualitativos.

Reproducimos de forma aproximada el cuadro de niveles emergentes que Emmeche (2004:119) aporta:

1. Estructuras disipativas, autoorganizadas (el cuerpo de la física)

2. Unidades fisiológicas, homeostáticas, con una pluralidad en cuanto al código genético e irritabilidad (el cuerpo de la biología)

3. "Enjambre" (swarm) de células vegetativas coordinando la comunicación multicelular con múltiples códigos orgánicos (el cuerpo de la investigación "evo-devo", evolution y development, esto es, las cuestiones de ontogenia y filogenia)

4. Seres automovientes, ciclos de acción-percepción, animación y cinestesia (el cuerpo de la zoología).

5. Lenguaje, especificidad cultural, mundo vivido (Lebenswelt).

6. Formación de hábitos, vida en instituciones societales (el cuerpo de la sociología).

En cualquier caso, las relaciones inter-niveles no parecen darse todas ellas, a su vez, en el mismo género (son no homomórficas). La emergencia del nivel biológico a partir del físico no contiene el mismo complejo de relaciones de dependencia que, pongamos, el nivel psíquico al social.

Se deja traslucir que la mente, a través del vehículo simbólico, es la instancia constructora, el sujeto que impone formalizaciones, que instaura las estructuras a partir de una estructura ya dada. La causalidad formal no es menos casualidad que la motriz, y es una instancia imprescindible para entender sistemas complejos de relación en la naturaleza. Así pues, en el ejemplo de la célula, vemos cómo ésta unidad biológica, siendo posterior a las moléculas que la originaron es, recíprocamente, la totalidad o estructura que controla a aquellas. En otro caso, siendo el proceso mental posterior o derivado del sustrato neurofisiológico del cerebro, una vez creado aquel, éste se puede ver alterado causalmente. 
Escribe Emmeche sobre la causación descendente: "The idea is that once constituted, the higher level is equipped with causal powers of its own, so that it is then able to inflict effects on the lower level having caused it" (Emmeche 2000:18). Esta formulación recuerda mucho la idea de un proceso dialéctico. Un término engendra a otro, pero éste a su vez, que era su opuesto, su negación una vez creado, refluye sobre la matriz generadora y la modifica. La matriz generadora no puede por menos de seguir creando pero lo va a hacer de otra manera. En términos del par estructura-función, diremos que se produce una dialéctica, a saber: la estructura es el resultado de una estabilización, algo así como la "congelación" de la función. Pero, de su parte, la función no puede llevarse a cabo sin la base o matriz de estructuras que nunca habrían existido sin una historia evolutiva previa. Es evidente que una psicobiología del conocimiento es un pleonasmo: hablar de psicobiología implica conceder un determinado papel al conocimiento, incluso al conocimiento consciente que, en el límite, nos remitiría al problema mismo del origen de la vida.

No se puede sostener ya que la sensación sea el punto cero del psiquismo. Es evidente que pedimos el principio al suponer un origen del sujeto en un supuesto proceso psíquico elemental, atomístico en el cual ya hay implícito un sujeto, que es aquello que queríamos construir. La propia idea de una psicofísica, como yuxtaposición de dos sintagmas y de las dos ciencias correspondientes, se torna incomprensible. La transducción es la transformación de una modalidad energética en otra, ambas dadas en el mismo nivel categorial: el de la física. Pero entender metafóricamente la transducción como una suerte de cruce de frontera desde lo físico a lo mental, como se quiso hacer en la psicofísica, carece de sentido. Carece de sentido pues es, en efecto, un error categorial (1). Pero los puntos de vista solipsistas, a saber, los del psiquismo encapsulado, precisan de tales metáforas que se basan en errores categoriales (sólo admisibles en un "modo material de hablar"). Los enfoques encapsulados entienden que lo exterior es solo un factor activador (triggering rol), como los de Maturana y Varela. Por el contrario, hemos visto más arriba los estudios de Freeman en los que la actividad de millones de neuronas se va expandiendo y hace que el cerebro se reorganice a sí mismo y le haga crecer en el proceso de la percepción. La percepción siempre es construcción, e incluso orgánicamente se debe entender como autoconstrucción: un cerebro sin perceptos es un cerebro sólo en potencia, carece de función.

Pero es que los órganos son órganos de individuos, y los individuos a su vez son órganos de la sociabilidad. Lleva razón Trevarthen cuando afirma que toda cognición es social (y no como se desprendería de la lista de "emergencias" de Emmeche anotada más arriba) un simple resultado final de niveles progresivamente incorporados, por posibilitación emergente. Lo social no es subconjunto del comportamiento. Hay una mediación social en todo acto, con lo cual no hay "átomos psíquicos" como la sensación. La mente, dice Toren, es la condición social de la vida y viceversa: conocer y vivir es lo mismo. La biosemiótica, aunque admite un materialismo emergente y un enfoque relacional (no encapsulado) del psiquismo, falla al no tomar en cuenta el carácter social de la cognición desde el principio. Un ejemplo señalado por Christina Toren (1993) es el concepto de socialización. Las teorías de la socialización son ahistóricas. La cognición ha de entenderse como un proceso microhistórico y encarnado. El puente entre la naturaleza y la cultura del que hablamos desde el principio de este artículo es un puente que debe estar alzado por la psicología, por una teoría del sujeto, un sujeto encarnado. Los biosemióticos, como Emmeche, reconstruyen esa historia social de la mente dentro de un marco genérico de intercambios simbólicos. Lo social "emerge" de la red simbólica. A diferencia de los cognitivistas y demás mentalismos encapsulados, los biosemióticos no consideran que "los significados habitan en la cabeza" de los sujetos. 
Pero un emergentismo no es un historicismo. La construcción de los significados a cargo de triángulos (símbolo, simbolizado, interpretante) cada vez más amplios puede formularse más allá de la historia, como el crecimiento de una planta que es un mero despliegue de fases dentro del ciclo de vida de la planta y del ciclo de existencia de la especie. El significado no es una "cosa" metida o albergada dentro de una cabeza; antes bien, es un acto antes que un hecho sustantivo. Producir significados es una subespecie de la acción del sujeto. Un acto (interno, en el caso del pensamiento, o externo, en el caso de acciones observables) nos remite a una serie de actos pasados, coexistentes o futuros, con los que guarda una relación de dependencia conceptual. Los enfoques causalistas de la psicología, y en concreto de la psicología evolutiva, desenfocan su objeto, y más bien habría que entender las génesis de la mente, de los significados, en la díada madre-niño en términos de implicación: unos actos (al igual que sucede con las estructuras lingüísticas) presuponen otros actos en una dependencia interna. El enfoque hermenéutico y el interaccionismo se alían aquí con la biosemiótica a la hora de despojar las mentes humanas de significados, de contenidos mentalistas. Cuanto hay en la díada madre-niño es una red de implicaciones lingüísticas, no una caja negra que recibe inputs. En la medida en que admitimos que el ser humano es un ser social desde su nacimiento (e incluso antes, pues puede hablarse de una díada madre-feto) el problema del significado queda resuelto, o más bien, queda borrado como problema pues el significado "no aparece" (emergencia) sino que "ya estaba alli".

Provisionalmente, a propósito de la aparición de lo social, podemos distinguir estos tres enfoques.

Solipsista: lo social queda segregado. Los modelos no lo contemplan, sólo en el plano ontológicomas no en el metodológico- lo social aparece como una emergencia de las computaciones internas.

Biosemiótico: lo social como subespecie de lo semiótico. Los modelos lo contemplan como una variedad más, si bien "de alto nivel", en el proceso de instauración de triángulos semióticos (símbolo, simbolizado, interpretante) que recorre toda la psicobiología desde la escala de la aparición de vivientes (origen de la vida a partir del nivel molecular) hasta la "emergencia" de la consciencia o inteligencia.

Hermenéutico: lo social como prerrequisito de lo semántico. La red de implicaciones es la depositaria de los significados. El aislamiento metodológico de símbolos y de actos cognoscitivos es posterior a la misma red social, a priori ontológica de cualquier relación psicobiológica. En lugar de un emergentismo meramente ontológico (o postulado) o epistemológico, se rechaza de plano el emergentismo y se defiende que "todo es significación", "no hay niveles" como no sean niveles de lectura o de interpretación.

Esta distinción de tres enfoques apunta a una cuestión esencial en los estudios del desarrollo y la evolución: ¿qué concepto constituye el prius (requisito previo) en la aparición de los significados y en la demarcación entre naturaleza y cultura?

A nuestro entender los tres enfoques reseñados pecan de unilateralidad. El emergentismo postulado (u ontológico) es estéril por definición en cuanto que sobrevuela encima de los modelos cognitivos (computacionales, experimentales, etc.) y solo sirve de adorno justificativo e ideológico de los científicos cognitivos. El emergentismo metodológico reconstruye conceptos complejos (lo social, lo consciente, lo cultural) en términos más primitivos (el símbolo) con el peligro que conlleva que en estos términos primitivos no hayamos introducido subrepticiamente aquello que queríamos desplegar con nuestros modelos. En la historia de la psicología, como vimos de la mano 
de J.C. Loredo, esto aconteció con el falso término primitivo "sensación". El sujeto psicológico procedería a partir de las sensaciones, los "átomos del psiquismo", pero con la trampa de que las sensaciones ya eran el sujeto, lo presuponían. La biosemiótica, igualmente, entendida como emergentismo metodológico, corre también el peligro de emplear una noción de símbolo que ya presupone el sujeto. Únicamente su descomposición triangular y su enfoque relacional nos puede vacunar contra un mentalismo implícito en este candidato a constituirse en término primitivo.

Hemos pasado revista a estos enfoques con el fin de desbrozar el camino hacia el que nos parece un enfoque más acertado. Un enfoque constructivista por capas, es decir, estratificado jerárquicamente. En la tradición filosófica, la superación del monismo y de todos sus derivados podríamos encontrarla, después de Aristóteles y la Escolástica, en el filósofo alemán A. Schopenhauer. Su triple estratificación (causalidad, estímulos, motivos) evita cualquier implicación monista pues cada uno de los estratos (digamos: físico, biológico, mental) sólo de forma analógica es comprendido por los otros dos. Esto significa que uno de los estratos es irreductible a los otros, y que "en ciertos aspectos" el motivo se asimila a la causalidad física, o al estímulo biológico, pero "bajo otros puntos de vista" se trata de una relación entre fenómenos completamente diferente.

\section{Conclusiones: volviendo la mirada a Schopenhauer}

La gran aportación de la psicología bien podría ser, si tomamos en cuenta sus desarrollos más constructivistas y dialécticos, la destrucción del monismo. El monismo del siglo XIX aparece, fundamentalmente, como monismo fisicista o como monismo espiritualista. En el materialismo monista, una sola sustancia da lugar a realidades emergentes por procesos puramente físicoquímicos y evolucionistas. De otra parte, la reacción espiritualista -de forma casi inversa pero simétrica- defiende que una especie de alma o espíritu universal va produciendo realidades físicoquímicas y orgánicas diversas. Pero la historia misma de la psicología (y no la de las teorías metafísicas) destruye ambos puntos de vista y restaura un pluralismo ontológico. La realidad se dice de muchas maneras. Schopenhauer es un ejemplo de esto: el mismo impulso (Drang) o ímpetu inconsciente [erkenntnißloses Streben] en que consiste la voluntad -única cosa en sí, el verdadero trasfondo nouménico del mundo que nos representamos- se "transduce" en la materia, inerte, vegetal u orgánica, y se impone bajo formas de causalidad distintas. Si alguien se aferra a la causalidad mecánica, podrá ver -desde su reduccionismo implícito- a las otras causalidades como sui generis: el estímulo y el motivo. Pero si alguien como Schopenhauer, como gran escolástico que era, pese a su profesado ateísmo y kantismo, considera que los tres grados de causalidad expresan de forma pluralista la verdadera estructura dinámica del mundo, entonces estaremos mucho más próximos al panorama que la teoría de la evolución darwiniana y el origen de la psicología experimental nos iban a presentar. Un panorama pluralista, de categorías inconmensurables matemáticamente entre sí, aunque guardando relaciones analógicas. Schopenhauer no entendió nunca la dialéctica de su enemigo, Hegel. Pero su pluralismo "analógico", su elegante teoría de la causalidad psicológica bien habría ganado con la incorporación de la dialéctica. La voluntad transfinita, motivo de su idealismo (en todo lo demás Schopenhauer es manifiestamente un materialista) de haberse vuelto inmanente, acabaría por hacer efectiva una psicología dialéctica. Pero, evidentemente, entonces la filosofía de Schopenhauer -el último escolástico y materialista- no habría sido la que fue. Las categorías psicobiológicas darían los pasos que ni él ni Hegel dieron.

La cuestión decisiva de la filosofía schopenhaueriana estriba en su materialismo. El mundo "como representación", esto es, el único mundo que puede ser investigado por las ciencias naturales 
(incluyendo aquí la psicología y las neurociencias) se atiene, según él, a un estricto determinismo. Toda la investigación científica toma, desde el siglo XVII, como "primer analogado" la causalidad física determinista, para ir ascendiendo a estratos cada vez más elevados de causalidad sui generis: irritación y estimulación en biología, causación "descendente" o motivos en psicología, etc. Ahora bien, Schopenhauer careció de toda noción evolucionista, a pesar de sus grandes conocimientos en biología y ciencias naturales, y a pesar de ser un precursor de ideas clave como la idea de lucha por la supervivencia. En gran medida, por una cuestión epocal, el gran filósofo de Danzig no llegó a incorporar la contribución darwinista, a pesar de que su filosofía natural parecía pedirlo a gritos. Curiosamente fue su rival, Hegel, quien pudo ofrecer una teoría dialéctica puramente inmanente: las capas o estratos de realidad de los que hablamos se generan internamente unos a otros: Hay un "desarrollo" o movimiento en la materia, que da pie a su transformación esencial, esto es, que da origen, desde la mera materia mecánica, sucesivamente, al quimismo, a la vida y a la psique. Tampoco fue Hegel un darwinista y sin embargo, hay una teoría del despliegue de distintos tipos de causalidad que no precisa de un mundo en sí completamente separado del mundo de los fenómenos.

\section{Nota}

(1) Agradezco estas reflexiones al profesor J. C. Loredo de la U.N.E.D. (Madrid) y a la lectura de varios manuscritos suyos no publicados.

\section{Bibliografía}

Blanco, C. J. 1997, ¿Cómo se inventa una ciencia del significado? Arbor: Ciencia, pensamiento y cultura 619: 183-200.

Bueno, G., 1991. Primer ensayo sobre las categorías de las 'ciencias políticas'. Logroño: Biblioteca Riojana.

Charniak, 1984. Cognitive science is methodologically fine. En: W.Kintsch, J.Miller y P.G.Polson. Methods and tactics in cognitive science. Hillsdale, NJ: Lawrence Erlbaum, pp. 263-274

Dawkins, R. 2000. El gen egoísta: las bases biológicas de nuestra conducta. Barcelona: Salvat.

Díaz de Rada, A. y Velasco, H. 1996. La cultura como objeto. Signos 17: 6-12.

Dietrich, M.R. 1998. Paradox and persuasion: negotiating the place of molecular evolution within evolutionary biology. Journal of the History of Biology 31(1): 85-111.

Emmeche, C. 2000. Levels, emergence and three versions of downward causation. En: E.A. Andersen, et. al. (eds). Downward causation. Minds, bodies and matter. Århus: Aarhus University Press, pp. 13-34.

Emmeche, C. 2004. A-life, organism and body: the semiotics of emergent levels. En: M. Bedeau. et al. (eds.) Workshop and tutorial proceedings. IX International Conference on the Simulation and Synthesis of Living Systems (Alife IX), Boston Mass, sep. 12, pp. 117-124.

Freeman, W. 1991. The physiology of perception. Scientific American 264(2): 34-41.

Hinde, R.A. 1991. A biologist looks at anthropology. Man 26(4): 583-608.

Hebb, D.O. 2002. El problema mente-cerebro. Un enfoque psicobiológico. Tecnos: Madrid.

Hubel, D.H. 1979. El cerebro. Investigación y ciencia 38: 9-19. 
Ingold, T. 1990. An anthropologist looks at biology. Man 25(2): 208-229.

Moya, E. 2005. Apriorismo, epigénesis y evolución. Revista de Filosofía 30(2): 61-68.

Robertson, A.F. 1996. The development of meaning: ontogeny and culture. Journal of the Royal Anthropological Institute 2(4): 591-610.

Sánchez, J.C. y Loredo, J.C. 2005. Psicologías para la evolución. Catálogo y crítica de los usos actuales de la selección orgánica. Estudios de Psicología 26(1): 105-126.

Schopenhauer, A. 2004. El mundo como voluntad y representación. Madrid: Trotta.

Toren, C. 1993. Making history: the significance of childhood cognition for a comparative anthropology of mind. Man 28(3): 461-478.

Wilkins, J.S. 1998. What's in a Meme? Reflections from the perspective of the history and philosophy of evolutionary biology. Journal of Memetics 2(1): 2-33.

Recibido el 4 Ago 2012

Aceptado el 25 Nov 2012 